\title{
Electrocoagulation of biliary papillomatosis during choledochoscopy
}

A 39-year-old woman was admitted to our hospital with pain in the right upper quadrant for more than 2 months. Magnetic resource imaging (MRI) showed that the patient had liver calcification, dilatation of the intrahepatic bile duct and upper part of the extrahepatic bile duct, and hepatic parenchymal nodules (ฉFig.1). The patient had undergone cholecystectomy for gallstones a year previously. For further diagnosis and treatment, we decided to perform biliary exploration.

During the procedure, there were no obvious stones seen but many papillary neoplasms with silt-like mucus were seen in the hilar and intrahepatic bile ducts on choledochoscopy (> Fig.2), which were thought to be biliary papillomatosis [1]. A biopsy was taken, which confirmed the diagnosis ( $\triangleright$ Fig. 3 ). Biliary papillomatosis is a rare and fatal disease characterized by multiple papillary tumors of variable distribution and extent in the intrahepatic and/or extrahepatic biliary tree [2, 3]. In an effort to destroy the tumors, 6 weeks later, we performed cholangioscopic electrocoagulation through a T-tube tract ( $\vee$ Video 1$)$. With there being little bleeding during the endoscopic operation, we re-inserted a T-tube into the common bile duct, and the patient returned to the ward safely.

Planned follow-up of the patient by choledochoscopy 3 weeks later showed that the visible bile duct silt-like mucus had disappeared, the hilar and intrahepatic bile ducts were smooth with some scarring visible, but there was no evidence of bile duct papilloma ( $\mathbf{F i g . 4}$ ). The patient was discharged from the hospital after a period of time.

Endoscopy_UCTN_Code_TTT_1AR_2AF

\section{Acknowledgments}

The authors wish to thank the Young Scholar's Scientific Research Fund of Sichuan University, China (2017SCU11057) for their support.

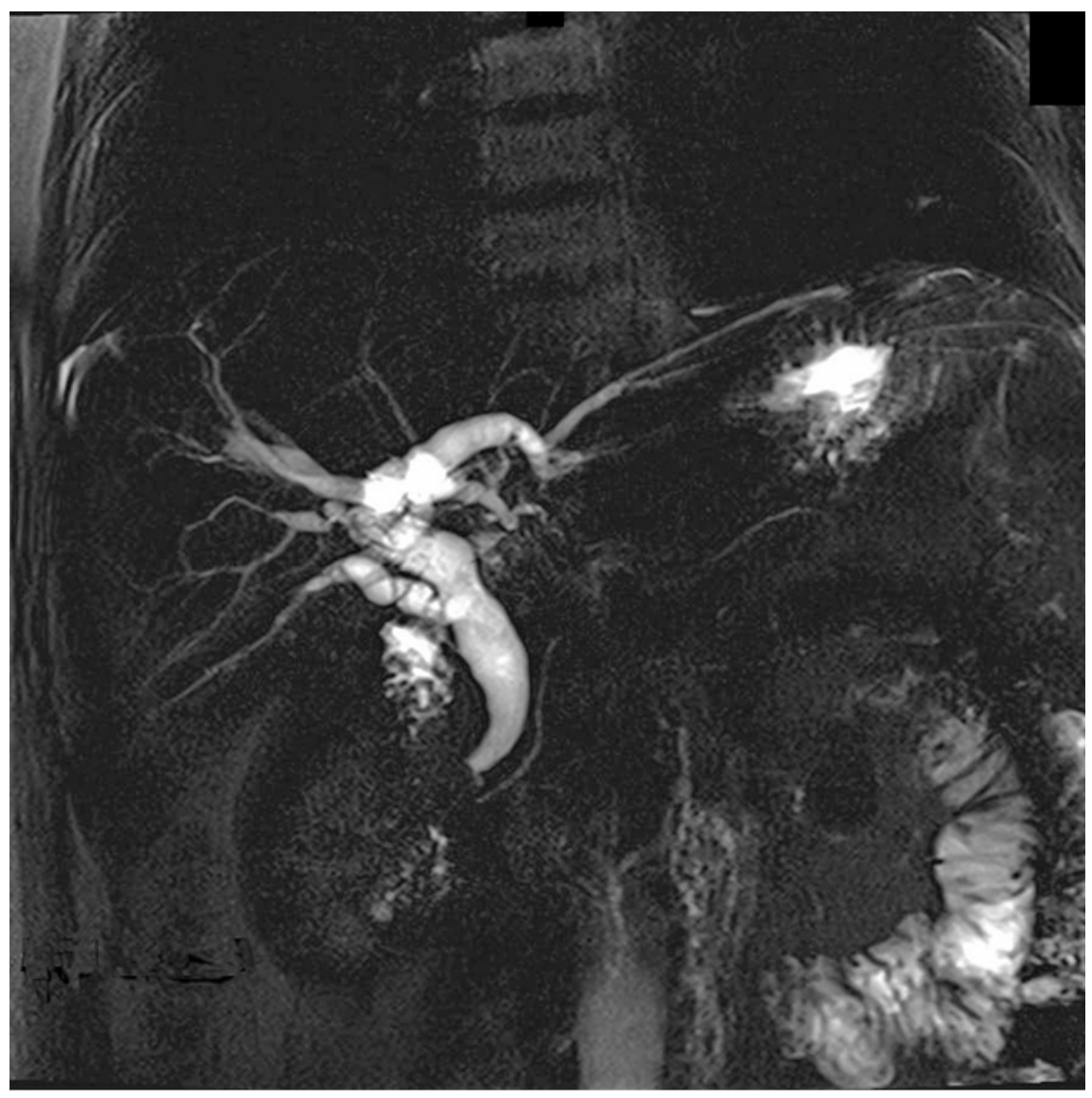

- Fig. 1 Magnetic resonance image showing dilatation of the bile ducts and hepatic parenchymal nodules.
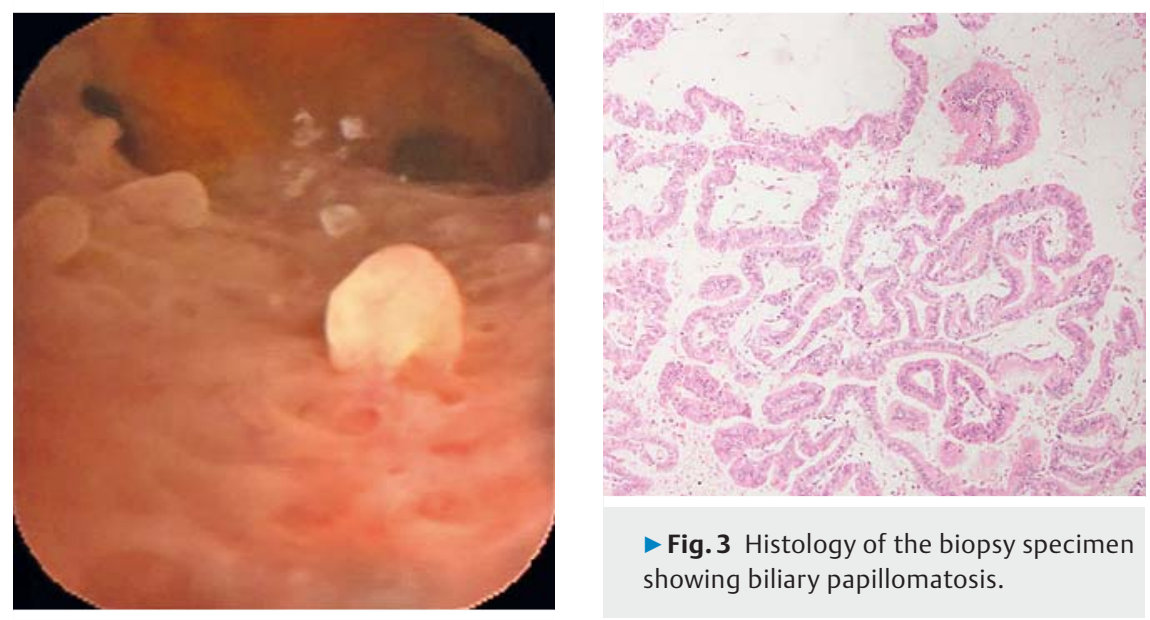

> Fig. 3 Histology of the biopsy specimen showing biliary papillomatosis.
> Fig. 2 Choledochoscopy view showing papillary neoplasms in the intrahepatic bile duct. 


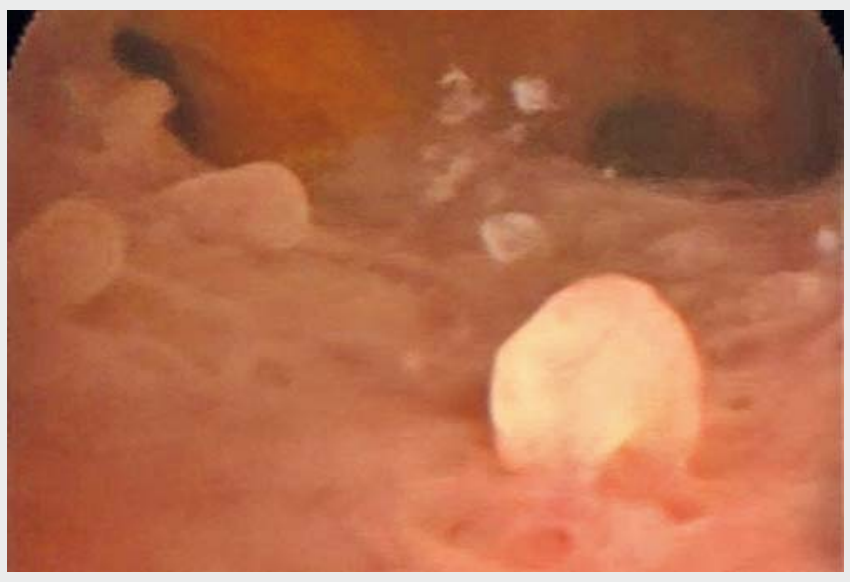

Video 1 Choledochoscopy showing many papillary neoplasms in the hilar and intrahepatic bile ducts. Cholangioscopic electrocoagulation is performed in an effort to destroy the tumors. Follow-up choledochoscopy shows the procedure was a success.

\section{Competing interests}

None

\section{The authors}

\section{Xianghong Zhou", Chuncheng Wu*, Chi Yuan, Bing $\mathrm{Hu}$}

Department of Gastroenterology, West China Hospital, Sichuan University, China

\section{Corresponding author}

\section{Bing Hu, MD}

Department of Gastroenterology, West China Hospital, Sichuan University, No. 37 Guo Xue Alley, Chengdu 610041, Sichuan Province, China hubingnj@163.com

\section{References}

[1] Lam CM, Yuen ST, Yuen WK et al. Biliary papillomatosis. Br J Surg 1996; 83: 1715 1716

[2] Lee SS, Kim MH, Lee SK et al. Clinicopathologic review of 58 patients with biliary papillomatosis. Cancer 2010; 100: 783-793

[3] Gunven P, Gorsetman J, Ohlsen H et al. Sixyear recurrence free survival after intraluminal iridium-192 therapy of human bilobar biliary papillomatosis - A case report. Cancer 2000; 89: 69-73

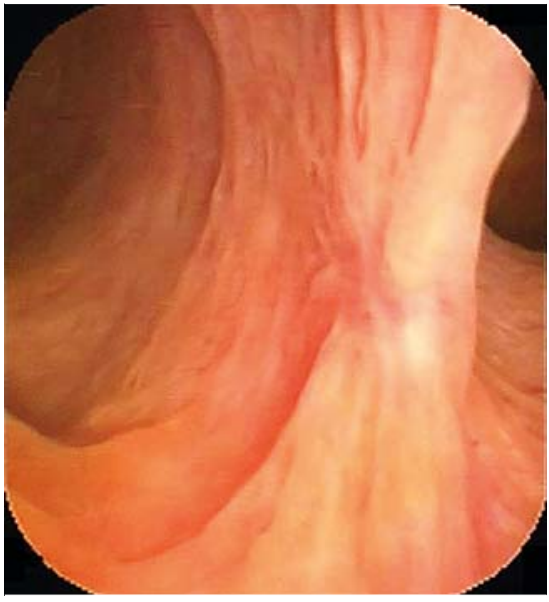

- Fig. 4 Choledochoscopy view showing that the hilar and intrahepatic bile ducts were smooth although with some scarring.

\section{Bibliography}

DOI https://doi.org/10.1055/a-0824-6195

Published online: 18.1.2019

Endoscopy 2019; 51: 390-391

(c) Georg Thieme Verlag KG

Stuttgart · New York

ISSN 0013-726X

\section{ENDOSCOPY E-VIDEOS}

https://eref.thieme.de/e-videos

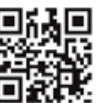

Endoscopy E-Videos is a free access online section, reporting on interesting cases and new techniques in gastroenterological endoscopy. All papers include a high quality video and all contributions are freely accessible online.

This section has its own submission website at

https://mc.manuscriptcentral.com/e-videos

* Joint first authors 